\title{
Vitamin D nutrition in pregnant Nigerian women at term and their newborn infants
}

\author{
F OKONOFUA, S HOULDER, J BELL, P DANDONA
}

\author{
From the Department of Chemical Pathology and Human Metabolism, Royal Free Hospital and School of \\ Medicine, London
}

SUMMARY In view of the high incidence of rickets in infants of women practising purdah (the use of veils) in northern Nigeria we conducted a study on plasma calcium, phosphate, and serum 25-hydroxyvitamin D (25 OHD) concentrations in pregnant Nigerian women and in cord blood obtained from the newborns. Plasma calcium, phosphate, and serum 25 OHD concentrations were lower in practising women and their newborns than those not practising purdah and their infants, respectively. The concentrations of $25 \mathrm{OHD}$ in all Nigerian woman were greater than those observed in caucasian women in the United Kingdom. These data emphasise the role of exposure to sunshine in regulating serum $25 \mathrm{OHD}$ concentrations and the adverse effect of deliberate exclusion of sunshine and are consistent with previous data indicating hypovitaminosis $\mathrm{D}$ in purdah clad women and their newborns in Saudi Arabia. These data do not, however, provide an explanation for the pathogenesis of the high incidence of neonatal rickets and tetany in infants born of purdah clad woman as these women have $25 \mathrm{OHD}$ concentrations greater than those in caucasian women in the United Kingdom.

The religious practice of purdah (the use of veils by women) has recently been shown to be associated with a high prevalence of vitamin D malnutrition in women in Saudi Arabia. ${ }^{12}$ As infants of Muslim women practising purdah in northern Nigeria are known to develop neonatal tetany and congenital rickets ${ }^{34}$ whereas infants of non-purdah women do not present with such problems, we examined the possibility that the practice of purdah may cause vitamin D malnutrition in Nigerian women. This is important as hypovitaminosis $\mathrm{D}$ during pregnancy is related to the occurrence of myopathy and pathological fractures in women ${ }^{5}$ and neonatal tetany and rickets in infants. ${ }^{6-8}$ It may also be associated with secondary hyperparathyroidism in neonates. ${ }^{9}$ As expected, women practising purdah and their infants had noticeably lower serum 25-hydroxyvitamin D (25 OHD) concentrations than those who did not and their newborns. Despite this difference the concentrations of $25 \mathrm{OHD}$ in these women were appreciably greater than those found in caucasian and Asian women in the United Kingdom. These observations raise some important and fundamental questions about the pathogenesis of the high incidence of rickets in infants of women practising purdah in Nigeria.

\footnotetext{
Accepted for publication 23 January 1986
}

\section{Material and methods}

Twenty non-Muslim non-purdah woman and 10 Muslim women who had been kept indoors in purdah throughout their pregnancies were included in this investigation. The blood samples were obtained from women attending the Universities of Ilorin, Benin, and Ife Teaching Hospitals in Nigeria. A clear history of having been confined in purdah before and during pregnancy was obtained from these women; most of them had been covered in thick dark dresses and veils during the pregnancies. Detailed information obtained from the mothers included dietary and religious practices, confinement in purdah, family history of rickets, and socioeconomic status based on the husband's occupation, years of schooling, and type of housing.

Blood was obtained from the mothers at the time of vaginal delivery. Cord blood was obtained while the placenta was still in situ by cutting the cord with a sterile blade and allowing the blood to drip into a $\stackrel{9}{?}$ tube. Some of the blood was heparinised, centrifuged, and separated into plasma, while the rest was allowed to clot, centrifuged, and separated into serum. Samples were stored at $-20^{\circ} \mathrm{C}$ until analysis.

Plasma samples were used for the measurement of 
Plasma concentrations of calcium, phosphate, alkaline phosphatase, and albumin in cord and maternal samples in purdah and non-purdah women (values are expressed as median and (range))

\begin{tabular}{llll}
\hline Population studied & Corrected calcium (mmol ll) & Phosphate (mmol/l) & Alkaline phosphatase (IU/l) \\
\hline Purdah & $2 \cdot 17$ & $0 \cdot 84^{* *}$ & 119 \\
(maternal) & $(1 \cdot 97-2 \cdot 32)$ & $(0 \cdot 70-1 \cdot 10)$ & $(99-226)$ \\
Non-purdah & $2 \cdot 36^{*}$ & $1 \cdot 30^{* *}$ & 201 \\
(maternal) & $(2 \cdot 13-2 \cdot 53)$ & $(0 \cdot 76-1 \cdot 76)$ & $(78-312)$ \\
Purdah & $2 \cdot 52^{*}$ & $1 \cdot 16^{* *}$ & 186 \\
(cord) & $(2 \cdot 14-2 \cdot 68)$ & $(0 \cdot 96-1 \cdot 86)$ & $(128-301)$ \\
Non-purdah & $2 \cdot 88^{*}$ & $1 \cdot 86^{* *}$ & 199 \\
(cord) & $(2 \cdot 50-3 \cdot 26)$ & $(0 \cdot 24-2 \cdot 78)$ & $(116-301)$ \\
\hline
\end{tabular}

"p < 0.002, **p < 0.004; "purdah" v "non-purdah".

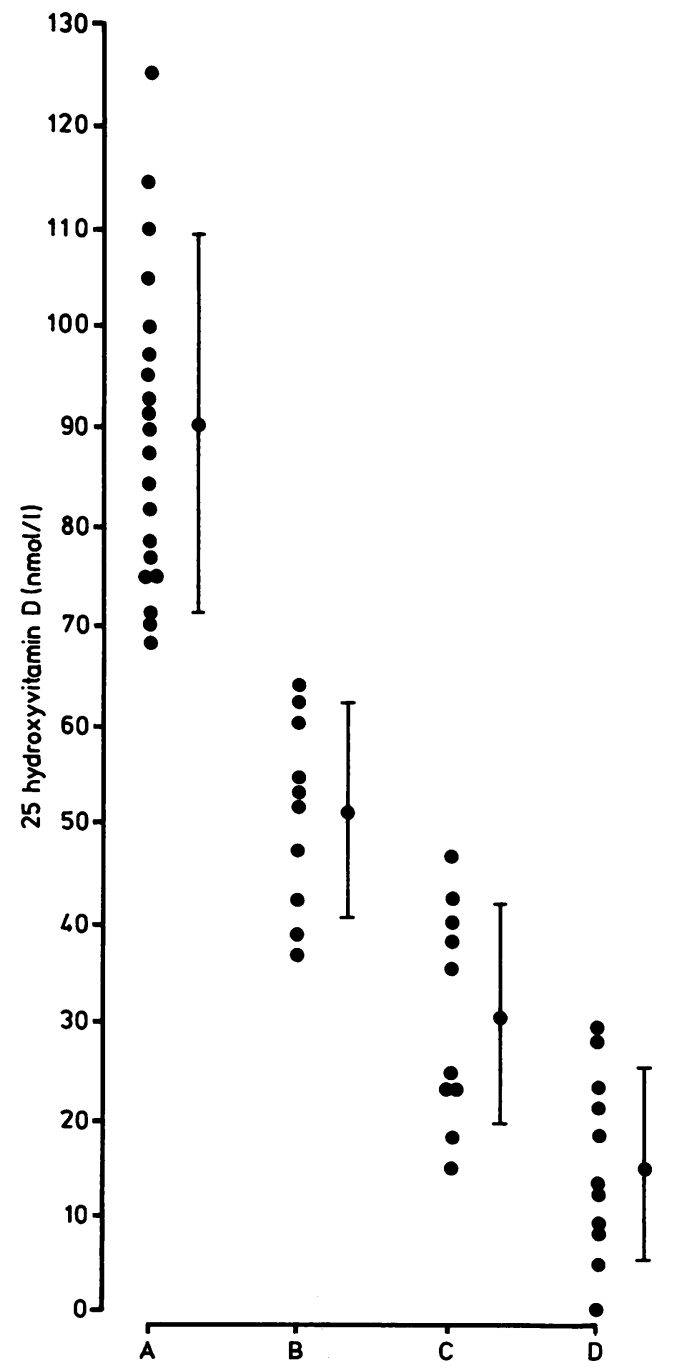

Fig. $125 O H D$ concentrations in maternal blood during labour in Nigerian non-purdah (A), Nigerian purdah (B), London caucasian (C), and London Asian (D) women, expressed as (nmol/l); mean (SD). calcium, phosphate, alkaline phosphatase, and albumin on an SMAC Technicon Autoanalyser. The serum concentration of 25 OHD was measured by the method modified from that of Preece et al, which entailed a preparatory chromatographic step followed by a protein binding step. ${ }^{10}$ Intra-assay variation in this assay is $8 \%$ and inter assay variation $<12 \%$. Statistical analysis was carried out by non-parametric statistics, Mann-Whitney U test, and Student's $t$ test, as appropriate.

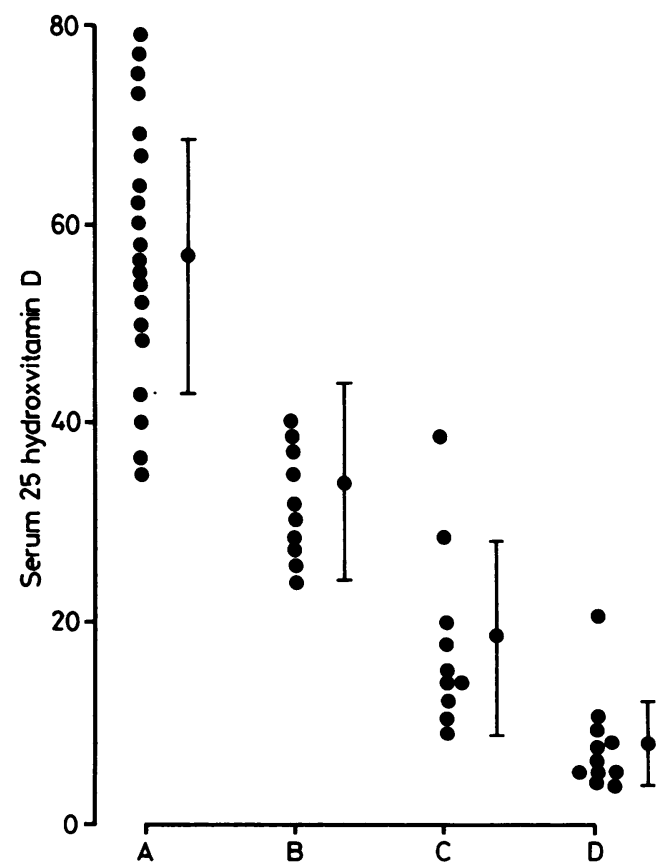

Fig. 225 OHD concentrations in cord blood of infants of Nigerian non-purdah $(A)$, Nigerian purdah (B), London caucasian (C), and London Asian (D) mothers, expressed as (nmol/l); mean (SD). 


\section{Results}

Women confined to purdah had significantly lower calcium and phosphate concentrations than those not practising purdah (Table). Some of the women practising purdah had low albumin concentrations; the difference in plasma calcium concentrations in the two groups persisted in spite of the "correction" aimed at compensating for albumin concentrations. Alkaline phosphatase activity, though higher in the nonpurdah women, was not significantly different from that in the purdah women.

Calcium and phosphate concentrations in plasma obtained from cord blood samples from neonates of purdah women were significantly lower than those from neonates of non-purdah women. There was no significant difference in albumin concentrations or alkaline phosphatase activity between cord plasma samples from these two groups (Table).

The mean 25 OHD concentration (mean: 53; range: 37-64 nmol/1 (mean 20; range: $15-25 \mathrm{ng} / \mathrm{ml})$ ) in sera of purdah practising women was significantly lower $(p$ $<0.002)$ than that in women not practising purdah (mean: 90; range: $68-150 \mathrm{nmol} / 1$ (mean 37 ; range: 26-60 ng/ml)) (Fig. 1). 25 OHD concentrations in all neonates (cord sera) were lower than those in sera of their respective mothers. The mean 25 OHD concentration in cord sera of neonates born of woman practising purdah (mean: 31 ; range: $24-59 \mathrm{nmol} / 1$ (mean 13; range: $10-24 \mathrm{ng} / \mathrm{ml})$ ) was significantly lower $(\mathrm{p}<$ $0.002)$ than that in neonates born of women not practising purdah (mean: 58 ; range: $35-79 \mathrm{nmol} / \mathrm{l}$ (mean 23; range: 14-32 ng/ml)) (Fig. 2). All 25 OHD concentrations, both in maternal and cord plasma from the purdah and non-purdah groups, were significantly greater than those found in caucasians, Asian mothers, and neonates at The Royal Free Hospital in London (Fig. 1).

\section{Discussion}

This study shows that plasma $25 \mathrm{OHD}$ concentrations were high in pregnant Nigerian women not confined in purdah. Maternal 25 OHD concentrations in nonpurdah Nigerian women were much higher than those found by Heckmatt et al, ${ }^{11}$ Dent and Gupta, ${ }^{12}$ and ourselves $^{9}$ for caucasian women in the United Kingdom. This is despite the fact that the non-purdah Nigerian women were mostly drawn from the lower socioeconomic groups and were therefore unlikely to be as well nourished as their caucasian counterparts. Clearly, this means that exposure to sunlight is a dominant mechanism for vitamin D homeostasis in man.

This point is further supported by the fact that plasma vitamin D concentrations in this study were significantly lower in women confined in purdah. The purdah system is practised in the Moslem community in Nigeria and entails the confinement of married women to their homes. When they do go out, they are covered with a thick dark dress and a veil, thus limiting their exposure to sunlight. The lower concentrations of $25 \mathrm{OHD}$ in the purdah clad women was clearly attributable to inadequate exposure to sunlight. The median concentration of $25 \mathrm{OHD}$ in purdah women in this study was within the caucasian range, but much higher than the values published for vegetarian Asians in the United Kingdom. Although no clear deficiency of 25 OHD was shown in the purdah women, this study identified a population that is clearly susceptible to the development of vitamin D deficiency. Such susceptibility might become overt if additional factors, such as severe malnutrition or repeated pregnancies, were to operate. A more extensive study of this population may, indeed, show some women with a clear cut deficiency of this vitamin.

This study also showed that 25 OHD in cord blood was consistently lower than that in maternal blood in both purdah and non-purdah women. This confirms the concept of the concentration dependent passage of this vitamin across the placenta, as has been shown in caucasian, ${ }^{7}$ Asian vegetarian, ${ }^{912}$ and Saudi Arabian women. $^{1}$ It refutes the findings of Heckmatt et al, ${ }^{11}$ who found consistently higher cord concentrations of 25 OHD when maternal concentrations were correspondingly low: differences in assay techniques may have accounted for these differences.

The surprising and discordant fact, however, is that in both purdah clad and non-purdah clad women 25 OHD concentrations were significantly greater than those in caucasian and Asian ${ }^{7912}$ women in the United Kingdom and purdah clad women in Saudi Arabia. ${ }^{1}$ This suggests that even purdah clad Nigerian women, despite greater skin pigmentation, have a greater effective exposure to sunlight than caucasian women in Britain; why the purdah clad Nigerian woman have significantly lower calcium and phosphate concentrations than both caucasians in the United Kingdom and non-purdah clad women in Nigeria remains, however, unexplained. Whether the eating habits of purdah clad women in this study lead to concomitantly diminished dietary calcium and phosphate intake is an issue that requires further investigation. A similar discrepancy was observed when we examined the data obtained from cord sera. 25 OHD concentrations in cord sera of neonates from purdah clad Nigerian women were significantly lower than those from babies of non-purdah clad women; they were, however, greater than those observed in caucasian newborns: yet, their calcium concentrations were lower than those in non-purdah Nigerian and caucasian pregnant women. Whereas the increased incidence of neonatal hypocalcaemia and tetany are 
understandable in Asian babies in the United Kingdom and in Saudi Arabian babies, the occurrence of hypocalcaemia in Nigerian babies remains unexplained. It should be mentioned that plasma calcium concentrations in non-purdah clad Nigerian women in our study were similar to those reported by Olatunbosun et al. ${ }^{4}$

These observations may again be due either to concomitant calcium malnutrition or to one of several biological mechanisms: a lower conversion rate of 25 $\mathrm{OHD}$ to $1,25(\mathrm{OH})_{2} \mathrm{D}$ in Nigerians; a diminished response of the enterocyte to $1,25(\mathrm{OH})_{2} \mathrm{D}$; a diminished response of parathyroid hormone hypersecretion to hypocalcaemia; a diminished response of end organs to secondary hyperparathyroidism.

To date there has been no report of racial differences affecting any of the above mechanisms. We are currently investigating whether the relations between calcium, $25 \mathrm{OHD}, 1,25(\mathrm{OH})_{2} \mathrm{D}$, and parathyroid hormone concentration among Nigerian women are different to those in caucasian woman.

We are grateful to Professors O Ogunbode and FME Drejomoah for permission to use their patients; to Drs DP Mikhailidis and V Fonseca for critical and constructive advice, and to Pamela Dale for preparing the manuscript.

\section{References}

${ }^{1}$ Serenius F, Elidressy I, Dandona P. Vitamin D nutrition in pregnant women at term and in newly born babies in Saudi Arabia. $J$ Clin Pathol 1984:37:444-7.
${ }^{2}$ Fonseca V, Tongia R, El-Hazmi M, Abu-Aisha H. Exposure to sunlight and vitamin D deficiency in Saudi Arabian women. Postgrad Med J 1984;60:19-21.

${ }^{3}$ Ojofeitimi EO, Tanimowo CM. Nutritional beliefs among pregnant Nigerian women. Int J Gynaecol Obstet 1978;18:66-9.

${ }^{4}$ Olatunbosun DA, Adeniyi FA, Adadevoh BK. Serum calcium, phosphorus and magnesium levels in pregnant and non-pregnant Nigerians. Br J Obstet Gynaecol 1975;82:568-71.

${ }^{5}$ Dandona P, Okonofua F, Clements RV. Osteomalacia during pregnancy presenting as pathological fractures during pregnancy in Asian women of high socioeconomic status. $\mathrm{Br}$ Med $J$ 1985;290:837-8.

${ }^{6}$ Moncrieff M, Fadahunsi TQ. Congenital rickets due to maternal vitamin D deficiency. Arch Dis Child 1974;49:810-11.

${ }^{7}$ Cockburn F, Belton NR, Purvis RJ, et al. Maternal vitamin D intake and mineral metabolism in mothers and their newborn infants. Br Med J 1980;3:11-14.

${ }^{8}$ Robinson D, Flynn D, Dandona P. Neonatal hyperphosphataemic rickets in an Asian infant. $\mathrm{Br}$ Med J 1985;290:1318-9.

${ }^{9}$ Okonofua F, Houlder S, Thomas M, Robinson D, O'Brien S, Dandona P. Elevated parathryoid hormone concentrations in pregnant Asian women and neonates. Metabolism (in press).

${ }^{10}$ Preece MA, O'Riordan JLH, Lawson DEM, Kodicek E. A competitive protein binding assay for 25 -hydroxycholecalciferol and 25-hydroxyergoacalciferol in serum. Clin Chim Acta 1974;54:235-42.

${ }^{11}$ Heckmatt JE, Peacock M, Davies AE, McMurray J, Isherwood DM. Plasma 25-hydroxyvitamin D in pregnant Asian women and their babies. Lancet 1979;ii:546-8.

${ }^{12}$ Dent CE, Gupta MM. Plasma 25-hydroxyvitamin D levels during pregnancy in caucasians and in vegetarian and non-vegetarian Asians. Lancet 1974;ii:1057-60.

Requests for reprints to: Dr P Dandona, Director, Metabolic Unit, Royal Free Hospital and School of Medicine, Pond Street, London NW3 2QG, England. 